Article

\title{
Family Environment Factors in Alcohol and Drug Misuse among Indonesian Students: Indonesia National Narcotics Sur- vey of Students
}

\author{
Nohan Arum Romadlona ${ }^{1, *}$, Budi Utomo ${ }^{1}$ and Purwa Kurnia Sucahya ${ }^{2,}$, Monalisa ${ }^{2}$ \\ 1 Knowledge Hub for Reproductive Health, Universitas Indonesia; arumnohan@gmail.com; \\ budi.utomo.ui@gmail.com \\ 2 Center of Health Research, Universitas Indonesia; purwa.sucahya@gmail.com; mona.lisa@ui.ac.id \\ * Correspondence: arumnohan@gmail.com
}

\begin{abstract}
The family environment has an important role in determining children's personality and behavior. This study examined the impact of the family environment on alcohol and drug misuse among Indonesian students. Data were obtained from the National Illicit Drug Use Survey of students in Indonesia in 2016, conducted in 18 provinces. The subjects were 35,340 students from 1284 schools and universities with an age range of 12-25 years. The survey used the self-administered modified NODC Structured Illicit Drug questionnaire. The results show that $13.7 \%$ of students ever drank alcohol and $2.1 \%$ of students misused drugs within the previous year. Among students who drank alcohol, $11 \%$ also used drugs. In the latter group, they were likely to have been victims of verbal and physical violence by their parents and never discussed any problems with their parents. Living with a family with existing risky behavior (alcohol drinking and/or drug misuse) was the strongest risk factor of alcohol drinking (aOR: 4.78; 4.27-5.37) and drug misuse (aOR: 2.32; 1.79-3.01). These results indicate that the family environment affects these risky behaviors in this target population. Making adjustments through parental support, control, and parenting style, particularly in initiating parent-child communication, may have benefits in preventing alcohol drinking and drug use in this target population.
\end{abstract}

Keywords: Alcohol drinking; Drug misuse; Family environment; Indonesian students

\section{Introduction}

Adolescence is a phase during which individuals continue to grow into maturity and are full of curiosity to try new things. The 2010 Census results show that Indonesia's population was 237.6 million, among whom $26.67 \%$ were adolescents aged $15-24$ years, which represents a demographic bonus that can affect social, economic, and national development aspects in the future if these people are healthy and productive [1]. Adolescent students are in a very vulnerable period, as this is a time of self-seeking and personality development. Health problems that occur in adolescents are associated with risky behavior such as smoking, drinking alcohol, using drugs, and having premarital sex [2].

Alcohol consumption leads to health problems and affects productivity. Young people are vulnerable to taking part in alcohol drinking and susceptible to its harmful effects due to this behavior. Hence, this issue has become a public health concern [3]. Adolescents who drink alcohol exhibit distinctive behaviors that affect themselves and other people and their surroundings, including their families, the environment, and their school and peers, even going as far as breaking the law. Alcohol consumption has an inverse association with the student's academic performance. Aggressive behavior, lower motivation, less attachment and commitment to learning, followed by underperformance at school, are commonly observed in students who consume alcohol [4]. A survey in 2012 showed 
that more Indonesian male adolescents (39.2\%) than female adolescents (5.9\%) drank alcohol [5]. In some areas of Indonesia, drinking alcohol has become part of the culture as a form of celebration on certain occasions even though consuming alcohol is prohibited by religion [6]. Furthermore, people who try alcohol tend to initiate other risky behaviors such as drug abuse.

Drug addiction is a health problem that leads to death and disability and creates a socioeconomic burden. Narcotics and psychotropic drugs are intended to be used for medicinal purposes. Uncontrolled use of these drugs can cause dependence as well as harmful effects to the users, including deteriorating physical function and mental alterations such as disturbances in perception, thinking, creation, and emotions that eventually change the person's behavior. Globally, the increasing prevalence of drug abuse can be seen from 2006 to 2013 [7]. Moreover, in Indonesia, an increasing percentage of drug users among adolescents can be seen, accounting for 24 to $28 \%$ [8,9]. This group is likely to suffer long-term impacts as they may spend more time involved in drug abuse.

The family environment has an important role in determining children's personality and behavior. Several studies show that alcohol and drug consumption may be influenced by family characteristics, schools, and peers or social groups [10-12]. A home environment with divorced parents and child-unfriendly behavior (verbal expressions, attitudes, and actions) could influence children's behavior in society. The quality of the parents' marriage, the level of family disagreement and conflict experienced by the child at home, coping mechanisms, and parent-child discussions of behavioral rules are seemingly important in forming the child's behavior. Marital conflict is associated with lower levels of parental monitoring of children and poorer affection and bonding [13]. This assumption was supported by some studies that demonstrated a link between family conflict and violence with a higher risk of alcohol and drug use among school-age children $[14,15]$. Furthermore, when a child experiences violence and family conflict at a young age, it may interfere with the development of peer relationships in school, which are unlikely to be positive [16].

Surveys related to behaviors and sensitive issues are still quite taboo in Indonesia. Surveys are difficult to carry out and conducted rarely, and highly underreported. The output of several surveys conducted in Indonesia mainly focused on finding out the prevalence of drugs, including descriptions of drug dealers and users in Indonesia. This study more deeply examines the association of family environment factors and student behavior on alcohol drinking and drug abuse in Indonesia, and addresses potential aspects for future prevention programs.

\section{Materials and Methods}

This study utilized secondary data from the National Database of Illicit Drug Use survey of students in Indonesia in 2016 conducted by the Indonesia National Narcotics Board (BNN) in collaboration with the Centre for Health Research at the University of Indonesia. The survey covered 18 provinces, including 11 priority provinces by the BNN based on indicators such as the prevalence of drug abuse in the general population, based on school level and geographic area representation. The distribution of samples was 35,340 students from 1284 junior and senior high schools and universities who were randomly selected based on the criteria. The survey used the self-administrated modified UNODC structured illicit drug use questionnaire to collect data $[17,18]$. The collected data included sociodemographic characteristics, illicit drug knowledge, sources of narcoticsrelated information, types of illicit drugs used and frequency of use, access to illicit drugs, smoking, and alcohol drinking. 


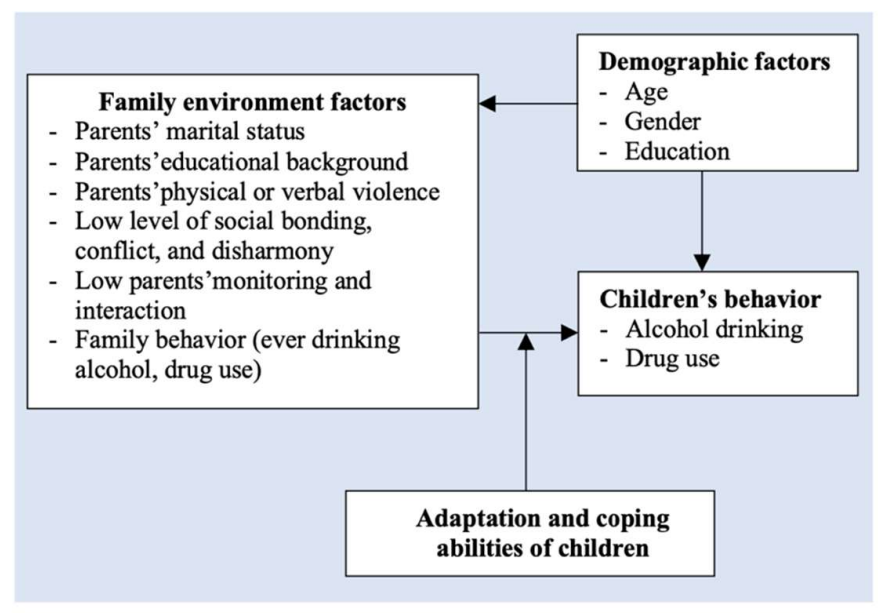

Figure 1. Modified-conceptual model on adaptation and coping abilities related to young adult alcohol use and family environment (Jannison 2016).

The two outcomes used in this analysis are alcohol drinking and drug use, defined by current prevalence (use within the past year) and excluding students who responded "do not know" or "do not remember". The selected respondents were students between 12 and 25 years old at junior and senior high schools and universities. The dependent variables, alcohol drinking and drug use, were categorical variables, and the logistic regression maximum likelihood method was considered appropriate. The logit model is appropriate when the issue of interest is to describe the odds of the outcome. Odds are defined as the ratio of the probability of one outcome to another. The odds ratio has two groups of binary data with probabilities of success $\mathrm{p} 1$ and $\mathrm{p} 2$, such that $\operatorname{logit}(\mathrm{p} 1)=\beta+\gamma$ and $\operatorname{logit}(\mathrm{p} 2)=\beta 0$, where $\beta 0$ and $\gamma$ are the parameters [19].

Family environmental factors were explained in a modified-conceptual model of adaptation and coping abilities related to young adult alcohol use and the family environment by Jennison (2016) [12]. Other mechanisms that describe risk factors with regard to the effect of experiencing interpersonal violence on alcohol consumption in adolescents can be seen in stress and coping theory developed by Lazarus and Folkman (1984). The hypothesis assumes that a student living with a family in which either or both parents had problems in their family would be more likely to engage risky behavior than a student living with an encouraging family. A correlation matrix was used to check for any multicollinearity between independent variables. The odds of alcohol drinking and drug use were assessed using multiple logistic regression, controlling for sociodemographic characteristics.

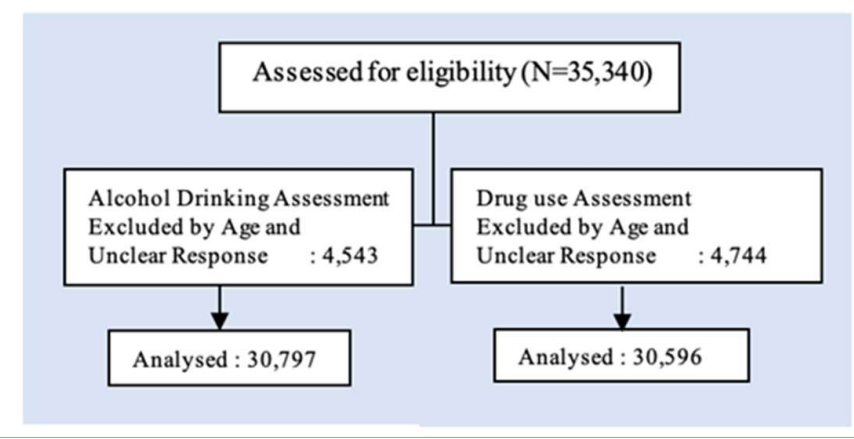

Figure 2. Participant flowchart. 
In this study, the family environment factors are the parents' marital status, parents' educational background, physical or verbal violence from the parents, low-level parental monitoring and interaction with the children, the opportunity to discuss serious problems with the parents, and family behaviors. Additional questions include parental restrictions, level of social bonding, and monitoring by parents.

Table 1. Definitions of variables.

\begin{tabular}{ll}
\hline Outcome variables & Definitions and Measurement \\
\hline Alcohol drinking & $\begin{array}{l}\text { Self-reported episodes of drinking any of eight alcoholic beverages more than one time in the } \\
\text { past year. Response options were no }(=0) \text { or yes }(=1) \text {. Total score was calculated, with higher } \\
\text { scores indicating higher levels of alcohol drinking (Cronbach's a }=0.8) .\end{array}$ \\
\hline $\begin{array}{l}\text { Self-reported use of any of } 36 \text { psychotropic substances mentioned in the questionnaire; also in- } \\
\text { cluded injected drugs tried more than one time in the past year. Response options were no }(=0) \\
\text { or yes }(=1) . \text { Total score was calculated, with higher scores indicating higher levels of drug use } \\
\text { (Cronbach's a }=0.7) .\end{array}$ \\
\hline
\end{tabular}

\section{Family factors}

Parents' marital status

Parents' education

Verbal violence

Physical violence

Restrictions

Low monitoring

Low bonding

Discuss serious problems

Family risky behavior
Current marital status of parents at time of survey. Discretization was made to create a binary response: not married (single, divorced), married, or living together.

Highest education level attained by father and mother.

Have you ever experienced one of these types of violence from parents? (Likert scale: never, rarely, often, very often):

- Cursing with dirty words

- $\quad$ Underestimating their abilities

- Insulting

Questions were categorized as binary: No = never experienced these types of violence; Yes = experienced at least one type of violence.

Have you ever experienced one of these types of violence from parents? (Likert scale: never, rarely, often, very often):

- $\quad$ Slapping/punching/kicking/hitting

- $\quad$ Being punished by withholding food

- $\quad$ Being hit by a belt or other rough object

- $\quad$ Being forced to work for money

Questions were categorized as binary: No = never experienced these types of violence; Yes = experienced at least one type of violence.

Have you experienced any of these conditions? (Likert scale: never, rarely, often, very often)

- $\quad$ Given many rules

- $\quad$ Had the right to play games or use a mobile phone revoked

- Was not allowed to hang out or going anywhere for a certain time

Questions were categorized as binary: No = never experienced any restrictions; Yes = experienced at least one restriction.

Have you experienced any of these conditions? (Likert scale: never, rarely, often, very often)

- $\quad$ Parents never call or are anxious if I get home late

- $\quad$ Parents didn't care where I went or when

- $\quad$ Parents never asked who my close friends are

Questions were categorized as binary: $(\mathrm{No}=$ never experienced little monitoring by parents; Yes = experienced at least one condition.

Have you experienced any of these conditions? (Likert scale: never, rarely, often, very often)

- $\quad$ Family never gives warmth and attention

- $\quad$ Family never shares stories and experiences

- $\quad$ Family never helps if there is a family member who has a problem

Questions were categorized as binary: No=never experienced these conditions; Yes = experienced at least one condition.

Students were asked whether they usually talked about personal problems with their parents; answers were grouped into two possibilities: dialogue (yes) and absence of dialogue (never).

Did at least one family member (father, mother, sibling, or close relative) consume alcohol or use drugs within the past year? 


\section{Results}

\subsection{Sociodemographic characteristics}

Among this analyzed population, a total of $13.7 \%$ of students $(n=30,797)$ identified as having drunk and $2.1 \%(n=30,596)$ as having taken drugs in the past year. Among students who drank alcohol, $11 \%$ also used drugs. Table 2 presents sociodemographic characteristics of alcohol and drug users. The majority were male between 19 and 25 years of age. Alcohol drinkers were more likely academy or university students living outside of Java-Bali, and drug users were more likely senior high school students living in JavaBali.

Table 2. Sociodemographic characteristics according to alcohol drinking and drug use among Indonesian students.

\begin{tabular}{|c|c|c|c|c|c|}
\hline \multirow{2}{*}{\multicolumn{2}{|c|}{ Sociodemographic }} & \multicolumn{2}{|c|}{$\begin{array}{l}\text { Alcohol Drinking } \\
\quad(n=4221)\end{array}$} & \multicolumn{2}{|c|}{$\begin{array}{c}\text { Drug Misuse } \\
\quad(n=619)\end{array}$} \\
\hline & & $\mathrm{N}$ & $\%$ & $\mathrm{~N}$ & $\%$ \\
\hline \multirow{2}{*}{ Sex } & Female & 764 & 18.2 & 104 & 16.8 \\
\hline & Male & 3457 & 81.9 & 515 & 83.2 \\
\hline \multirow{2}{*}{ Age } & $12-18$ & 1923 & 45.6 & 340 & 54.9 \\
\hline & $19-25$ & 2298 & 54.4 & 279 & 45.1 \\
\hline \multirow{3}{*}{ Current education } & Junior high school & 667 & 15.8 & 141 & 22.8 \\
\hline & Senior high school & 1648 & 39.0 & 276 & 44.6 \\
\hline & College/university & 1906 & 45.2 & 202 & 32.6 \\
\hline \multirow{2}{*}{ Region } & Java-Bali & 1392 & 33.0 & 238 & 38.4 \\
\hline & Outside Java-Bali & 2829 & 67.0 & 381 & 61.6 \\
\hline
\end{tabular}

3.2. Demographic background and family environment factors in relation to alcohol and drug misuse

Table 3 elaborates on the demographic background and family environment factors concerning alcohol drinking and drug use. Most of the students who drank alcohol and used drugs were living with both parents. Comparing the percentages of positive cases per total respondents, students who lived with highly educated parents, experienced low monitoring and bonding, and did not communicate about serious problems with their parents demonstrated a higher prevalence of alcohol drinking and drug use. Students who experienced verbal and physical violence and had a family member who engaged in alcohol drinking and drug use also showed a higher prevalence of alcohol drinking and drug use. Students in less restricted families showed a higher prevalence of engaging in these behaviors compared to students in strict families.

Table 3. Demographic background and family environment factors in relation to alcohol and drug misuse among students in Indonesia.

\begin{tabular}{|c|c|c|c|c|}
\hline \multirow{2}{*}{$\begin{array}{c}\text { Demographic Background and Family Envi- } \\
\text { ronment Factors }\end{array}$} & \multicolumn{2}{|c|}{$\begin{array}{l}\text { Alcohol Drinking } \\
\quad(n=4221)\end{array}$} & \multicolumn{2}{|c|}{$\begin{array}{l}\text { Drug Misuse } \\
\quad(n=619)\end{array}$} \\
\hline & $\mathbf{N}$ & $\%$ & $\mathbf{N}$ & $\%$ \\
\hline \multicolumn{5}{|l|}{ Parents' marital status } \\
\hline Married/living together & 3752 & 88.9 & 523 & 84.5 \\
\hline Not married & 444 & 10.5 & 92 & 14.9 \\
\hline \multicolumn{5}{|l|}{ Parents' education } \\
\hline Junior high school graduate or lower & 1359 & 32.2 & 193 & 31.2 \\
\hline Senior high school graduate & 1595 & 37.8 & 257 & 41.5 \\
\hline College/university graduate & 1146 & 27.1 & 146 & 23.6 \\
\hline \multicolumn{5}{|l|}{ Ever experience verbal violence } \\
\hline No & 2492 & 59.0 & 332 & 53.6 \\
\hline Yes & 1729 & 41.0 & 287 & 46.4 \\
\hline \multicolumn{5}{|l|}{ Ever experience physical violence } \\
\hline No & 2596 & 61.5 & 338 & 54.6 \\
\hline Yes & 1625 & 38.5 & 281 & 45.4 \\
\hline Restrictions & & & & \\
\hline
\end{tabular}




\begin{tabular}{ccccc}
\hline No & 1646 & 39.0 & 233 & 37.6 \\
\hline Yes & 2575 & 61.0 & 386 & 62.4 \\
\hline Low monitoring & & & & \\
\hline No & 2977 & 70.5 & 435 & 70.3 \\
\hline Yes & 1244 & 29.5 & 184 & 29.7 \\
\hline Low bonding & & & & \\
\hline No & 3517 & 83.3 & 502 & 81.1 \\
\hline Yes & 646 & 15.3 & 105 & 17.0 \\
\hline Piscuss serious problems & & & \\
\hline Yes & 2415 & 57.2 & 315 & 50.9 \\
\hline Never & 1769 & 41.9 & 296 & 47.8 \\
\hline Family risky behavior & & & \\
\hline No & 1503 & 35.6 & 228 & 36.8 \\
\hline Yes & 1800 & 42.6 & 225 & 36.3 \\
\hline
\end{tabular}

\subsection{Risk factors of alcohol drinking and drug misuse}

The odds of alcohol and drug use were calculated using multiple logistic regression statistical models, as shown in Table 4. After adjusting for the effects of potential confounding sociodemographic covariates in statistical models (age, gender, education) and having friends with risky behaviors, there was strong evidence that some family environment problems increased the prevalence of alcohol drinking and drug use among students in Indonesia.

Six family environment and demographic factors were highly associated with alcohol drinking among students. Having highly educated parents, experiencing verbal and physical violence, experiencing low bonding, never discussing serious problems with parents, and having a family member who drank alcohol or used drug had a major influence on students' drinking behavior. The strongest risk factor was having a family member who engaged in risky behavior $(\mathrm{AOR}=4.78 ; 95 \% \mathrm{CI}=4.27-5.37)$, followed by never having discussions with parents $(\mathrm{AOR}=1.51 ; 95 \% \mathrm{CI}=1.34-1.69)$ and experiencing physical violence by parents $(\mathrm{AOR}=1.42 ; 95 \% \mathrm{CI}=1.25-1.61)$.

In general, the family environment patterns were almost the same as those seen in students who used drugs. Parents' marital status, parental restrictions, low monitoring, and low bonding were not directly related to drug use behavior. Similar to the behavior of drinking alcohol, risky family behavior has a strong association with drug use behavior in students $(\mathrm{AOR}=2.32 ; 95 \% \mathrm{CI}=1.79-3.01)$.

Table 4. Adjusted odds ratio of family background characteristics according to alcohol and drug misuse among students in Indonesia.

\begin{tabular}{|c|c|c|c|c|c|c|}
\hline & \multicolumn{3}{|c|}{ Alcohol use } & \multicolumn{3}{|c|}{ Drug misuse } \\
\hline & AOR & \multicolumn{2}{|c|}{$95 \%$ CI } & AOR & \multicolumn{2}{|c|}{$95 \% \mathrm{CI}$} \\
\hline \multicolumn{7}{|l|}{ Parents' marital status } \\
\hline Married/living together & 1.000 & - & - & 1.000 & - & - \\
\hline Not married & 1.122 & 0.938 & 1.341 & $1.597^{*}$ & 1.116 & 2.285 \\
\hline \multicolumn{7}{|l|}{ Parents' education } \\
\hline Junior high school graduate or lower & 1.000 & - & - & 1.000 & - & - \\
\hline Senior high school graduate & 0.943 & 0.829 & 1.074 & 1.057 & 0.784 & 1.424 \\
\hline $\begin{array}{l}\text { College/university graduate } \\
\text { Experience verbal violence }\end{array}$ & $1.245^{*}$ & 1.083 & 1.431 & 0.979 & 0.697 & 1.376 \\
\hline No & 1.000 & - & - & 1.000 & & \\
\hline Yes & $1.201^{*}$ & 1.057 & 1.362 & $1.333^{*}$ & 1.098 & 1.803 \\
\hline \multicolumn{7}{|l|}{ Experience physical violence } \\
\hline No & 1.000 & - & - & 1.000 & - & - \\
\hline
\end{tabular}




\begin{tabular}{|c|c|c|c|c|c|c|}
\hline Yes & $1.418^{*}$ & 1.252 & 1.607 & $1.556^{*}$ & 1.169 & 2.074 \\
\hline \multicolumn{7}{|c|}{ Parental restrictions } \\
\hline No & 1.000 & - & - & 1.000 & & \\
\hline Yes & 0.878 & 0.758 & 1.017 & 0.901 & 0.629 & 1.289 \\
\hline \multicolumn{7}{|c|}{ Low monitoring } \\
\hline No & 1.000 & - & - & 1.000 & - & - \\
\hline Yes & $1.237^{*}$ & 1.047 & 1.461 & 1.162 & 0.794 & 1.702 \\
\hline \multicolumn{7}{|c|}{ Low bonding } \\
\hline No & 1.000 & - & - & 1.000 & - & - \\
\hline Yes & $1.362^{*}$ & 1.144 & 1.622 & 1.295 & 0.915 & 1.832 \\
\hline \multicolumn{7}{|c|}{ Discuss serious problems } \\
\hline Yes & 1.000 & - & - & 1.000 & - & - \\
\hline Never & $1.511 *$ & 1.347 & 1.695 & $1.811^{*}$ & 1.399 & 2.344 \\
\hline \multicolumn{7}{|c|}{ Family risky behavior } \\
\hline No & 1.000 & - & - & 1.000 & - & - \\
\hline Yes & $4.784^{*}$ & 4.266 & 5.366 & $2.321^{*}$ & 1.793 & 3.001 \\
\hline
\end{tabular}

\section{Discussion}

This study reveals the prevalence of drinking and drug use among students. Data from 2016 show that the prevalence of alcohol drinking in this group was $13.7 \%$, and $2.1 \%$ of students were involved in drug use. Looking at the trend as related to previous surveys (2006, 2009, and 2011), this indicates a consistent decrease in the prevalence of these risky behaviors, which is in line with the target of the United Nations Office on Drugs and Crime Country Program 2017-2020 Indonesia to continue to reduce the amount of drug abuse [8]. Based on the 2015-2019 RPJMN, the government set a target to reduce drug abuse prevalence by $0.05 \%$ every year [20].

Several studies have been conducted to determine the relationship between background characteristics in the family environment and alcohol and drug misuse. The findings are consistent with the prior literature, demonstrating a significant risk effect of family environmental factors on students' risky behavior. Experiences of verbal and physical violence, never discussing serious problems, and risky family behavior are associated with alcohol drinking and substance use. Students who have experienced verbal and physical violence from their parents have a higher tendency to consume alcohol and use drugs [21]. Adolescents who experience violence will likely suffer from stress and consume alcohol as self-medication [22].

Furthermore, there was a prior belief that using drugs or substances was beneficial as a maladaptive strategy to help regulate one's emotional state and cope with stress or the emotions around disruptive interpersonal violence [21,23,24]. In recent years, violence has been considered to be a much broader problem that involves the family, the community, and public health [25]. Experiencing violence at home is pivotal in compelling people to engage in alcohol drinking and drug use [14,21]. The family environment has a major influence on a child's development, therefore a deep understanding of how violence occurs in a family and its subsequent impact on the child should be emphasized. As a result of experiencing physical violence and witnessing domestic violence in the family, stress and trauma have a strong negative impact on a child's neurodevelopmental that may lead to early initiation of alcohol drinking and drug use [14,21].

Having parents who are too restrictive in allowing children to do their preferred activities, in the form of exaggerated rules such as playing games, and who forbid children to leave the house for certain periods is not related to the children's behavior with regard to consuming alcohol and using drugs. Children who obey their parents' rules tend to exhibit good behavior and are capable of resisting negative persuasion [26]. Low parental monitoring, as shown by a lack of anxiety or worry about whether their child comes home late at night and never reprimanding them, and never asking where the child is going and 
who their close friends are, is associated with alcohol consumption but not strongly with substance use, and similarly with low bonding.

Several studies have reported that the way families have an influence on the use of hard liquor and illicit drugs is directly through risky behavior and not through conventional bonding (indirect factor) [11]. Frequent conflict in a family can be emotionally draining and reduce the parents' ability to recognize and respond to their children's emotional needs [27]. Parent-child conflict is moderately associated with decreased warmth and support from parents, reduced behavioral control and monitoring, more verbal criticism and physical punishment [28], impaired parent-child relationships [29], and relatively higher parental psychological control and decreased monitoring [30,31]. However, several studies also reported that a lack of parental bonding was associated with illicit drug use $[32,33]$, whereas parental supervision and connectedness were protective factors for substance use [34].

Closeness between children and parents is shown by how frequently they discuss serious matters. In this situation, parents play a key role in transmitting attitudes, values, and beliefs about lifestyles that can stimulate positive outcomes in their children's cultural and school domains [35]. Children who do not get along with their parents tend to rely on friends as sources of information, which is sometimes unreliable. It is also harmful to children if they are surrounded by friends who engage in negative activities. Family environment and experiences, both positive and negative, affect children's social, emotional, and psychological well-being. Furthermore, conflict in a family that leads to poor communication creates less effective monitoring of adolescents' risky behavior [36]. A distant relationship between parents and children can lead to alcohol use, particularly in early adolescence [14]. Consistent involvement in family life and clear roles, as well as the presence of affection, can help adolescents form a stronger personality and avoid getting involved in negative things [11]. However, there is a notable assumption that the quality of family life plays an essential role in alcohol drinking behavior, not the structure of the family itself, whether the children live with unmarried or single parents or with both parents [14].

A prevention model with a family approach was promoted by the Healthy Indonesia Program launched by the Indonesia Ministry of Health in 2016 [37,38]. Unfortunately, very limited efforts to prevent smoking, alcohol drinking, and drug use among adolescents were mentioned. The Indonesia National Narcotics Board mainly focused on arresting drug dealers and users, and it is still controversial whether drug users should be treated as victims or criminals. Besides, alcohol drinking and drug abuse are still not the top priority, hence an increasing trend of such cases is inevitable.

It is clear that having a family member, either father, mother, or sibling, who ever consumed alcohol or drugs has a strong impact on a child's behavior. There is evidence in biopsychosocial research that various aspects of the family environment, including having a parent who drinks alcohol and early exposure to familial alcohol drinking, put children at greater risk of drug use and other related problems than children who were not exposed. Adolescents who have parents or siblings who drink alcohol or use drug tend to initiate similar risky behavior [39]. Children will always look to the behavior of those closest to them and see them as role models. The connection between alcohol drinking and behavioral problems at school involves exposure and vulnerability to a parental drinking problem [12].

Several limitations of the study should be noted. First, this study used a cross-sectional design that could not see causality. We were not able to detect which conditions precede the occurrence of the event. For example, it remains unclear whether certain negative life events, such as exposure to violence, contributes to drug use, or whether illicit drug involvement is the cause of the experience of violence. A longitudinal design is needed to address this shortcoming. Second, the data obtained tend to be underreported because the related behaviors in the survey are still taboo in Indonesia. Self-presentation issues may predispose adolescents to either exaggerate or minimize their risk-taking 
behaviors [40]. Third, the survey only covers BNN area programs, and some areas have a fairly high prevalence of drug use, so the findings must be interpreted with caution. Although students from a wide range of schools were included, the participants were restricted to students attending schools at the time of the survey. Therefore, the findings may not be generalizable to out-of-school adolescents.

\section{Conclusions}

This study addressed family factors and their impact on children's behavior. Parental support and monitoring have been shown to reduce the prevalence of adolescent drug use in many studies, but this does not apply if there are many conflicts between parents and children. In addition, the type of monitoring will vary. These findings have implications for preventive interventions to strengthen parental support and control and parenting styles with less conflict. The results affirm the importance of tending to parent-child communication and relations in the process of ameliorating their interactions. Parenting style is an essential interpersonal factor. As such, this study's results should be informative for parents, family practitioners, educators, and social policy planners. The program is not limited to prevention, but includes intervention for those who have experienced poor family circumstances with associated substance use. This could maximize the role of adolescent care centers in primary health care facilities at the subdistrict level in developing programs that provide training for family members on conflict resolution and encourage adolescents to participate in youth-oriented community activities. Future research might investigate the relationship between family characteristics and alcohol and drug use by conducting a longitudinal study to assess a broader range of information.

Author Contributions: All authors contributed equally to the manuscript. Conceptualization: NAR. Data curation: NAR, BU, PKS. Formal analysis: NAR, MN. Methodology: BU. Writing-original draft: NAR. Writing - review and editing: BU, PKS.

Funding: This research was funded by the University of Indonesia through International Research Collaboration Grant 2019.

Institutional Review Board Statement: As the study entailed analysis of secondary data containing no personally identifying information, an exempted review was granted by the Faculty of Public Health Research Ethics Committee. Ethical clearance was issued in 2014 by the Ethical Committee for Public Health Research of the Faculty of Public Health (IRB \#00006120) at Universitas Indonesia, after reviewing all study procedures.

Informed Consent Statement: Not applicable.

Data Availability Statement: The data are available on request from the corresponding author.

Acknowledgments: The authors acknowledge the Indonesia National Narcotics Board staff and the Centre of Health Research, University of Indonesia.

Conflicts of Interest: The authors declare no potential conflict of interest with respect to research, authorship, and/or publication of this article.

\section{References}

[1] BKKBN. Policy Brief Kajian Profil Penduduk Remaja (10-24 Tahun): Ada Apa dengan Remaja? Jakarta: 2011.

[2] Romadlona NA. Partner Discussion and Adolescent Health Risk Behaviors in Indonesia: Indonesia Demographic and Health Survey 2012. University of Indonesia, 2016.

[3] Ellickson PL, Mcguigan KA, Adams V, Bell RM, Hays RD. Teenage Alcohol Misuse: A Big Problem and a Different Solution. Rand Drug Policy Res Cent 1998:1-2.

[4] Cox J, Sagor R. At Risk Students: Reaching and Teaching Them by Jonas Cox, Richard Sagor / Kissly: Affordable Ebooks. 2nd ed. Larchmont, New York: Routledge; 2004. 
[6] Supit A, Mamuaja P, Pissu A. Alcohol consumption among college students in Minahasa, Indonesia: a cross-sectional study towards the formulation of intervention strategies. Int J Community Med Public Heal Supit A Al Int J Community Med Public Heal 2017;4:4630-7. https://doi.org/10.18203/2394-6040.ijcmph20175342.

[7] Huggins R. United Nations Office on Drugs and Crime. Encycl Drug Policy 2012. https://doi.org/10.4135/9781412976961.n354.

[8] UNODC. Country Programme 2017-2020 Indonesia “Making Indonesia safer from crime, drugs and terrorism.” Jakarta: 2017.

[9] BNN P. Penggunaan Narkotika di Kalangan Remaja Meningkat n.d. https://bnn.go.id/penggunaan-narkotika-kalanganremaja-meningkat/ (accessed August 19, 2021).

[10] Bahr SJ, Maughan SL, Marcos AC, Li B. Family, Religiosity, and the Risk of Adolescent Drug Use. J Marriage Fam 1998;60:979. https://doi.org/10.2307/353639.

[11] Fraser M. Family, School, and Peer Correlates of Adolescent Drug Abuse. Soc Serv Rev 1984;58:434-47. https://doi.org/10.1086/644217.

[12] Jennison KM. The impact of parental alcohol misuse and family environment on young people's alcohol use and behavioral problems in secondary schools. J Subst Use 2014;19:206-12. https://doi.org/10.3109/14659891.2013.775607.

[13] Ellis DA, Zucker RA, Fitzgerald HE. The role of family influences in development and risk. Alcohol Health Res World 1997;21:218-26.

[14] Carvalho V, Pinsky I, Silva RADSE, Carlini-Cotrim B. Drug and alcohol use and family characteristics: a study among Brazilian high-school students. Addiction 1995;90:65-72. https://doi.org/10.1046/j.1360-0443.1995.9016510.x.

[15] Espelage DL, Hong JS, Valido A. Associations Among Family Violence, Bullying, Sexual Harassment, and Teen Dating Violence. Adolesc Dating Violence 2018:85-102.

[16] Ehrensaft MK. Intimate partner violence: Persistence of myths and implications for intervention. Child Youth Serv Rev 2008;30:276-86. https://doi.org/10.1016/j.childyouth.2007.10.005.

[17] UNODC. Conducting School Surveys on Drug Abuse Global Assessment Programme on Drug Abuse (GAP) Conducting School Surveys on Drug Abuse 2013.

[18] UNODC. Final Independent project evaluation of the“Promoting Alternatives to Incarceration for Convicted Drug Users, including Rehabilitation and Probation" (Forming part of the Sub-Programme 5 on Drugs and HIV of the Indonesia Country Programme 2012-2016). New York: 2017.

[19] Powers DA, Xie Y. Statistical Methods for Categorical Data Analysis: 2nd Edition. Second Edi. Bingley, UK: Emerald Group; 2008.

[20] Kementerian Kesehatan. Infodatin Pusat Data dan Informasi Kementrian Kesehatan 2017: Narkoba. Jakarta: 2017.

[21] Yi S, Poudel KC, Yasuoka J, Palmer PH, Yi S, Jimba M. Risk vs. protective factors for substance use among adolescents in Cambodia. J Subst Use 2011;16:14-26. https://doi.org/10.3109/14659890903531261.

[22] Peleg-Oren N, Cardenas GA, Comerford M, Galea S. Exploratory study on the association between interpersonal violence experiences and alcohol use among adolescents. Soc Work Res 2013;37:277-85. https://doi.org/10.1093/swr/svt016.

[23] Kilpatrick DG, Acierno R, Saunders B, Resnick HS, Best CL, Schnurr PP. Risk factors for adolescent substance abuse and dependence: Data from a national sample. J Consult Clin Psychol 2000;68:19-30. https://doi.org/10.1037/0022-006X.68.1.19.

[24] Dube SR, Miller JW, Brown DW, Giles WH, Felitti VJ, Dong M, et al. Adverse childhood experiences and the association with ever using alcohol and initiating alcohol use during adolescence. J Adolesc Heal 2006;38:444.e1-444.e10. https://doi.org/10.1016/j.jadohealth.2005.06.006.

[25] James J, Pamela M. Epidemiology of alcohol-related violence. Alcohol Health Res World 1993;17:93.

[26] Guo J, Hawkins JD, Hill KG, Abbott RD. Childhood and adolescent predictors of alcohol abuse and dependence in young adulthood. J Stud Alcohol 2001;62:754-62. https://doi.org/10.15288/jsa.2001.62.754.

[27] Fincham FD. Understanding the Association Between Marital Conflict and Child Adjustment: Overview. J Fam Psychol 
1994;8:123-7. https://doi.org/10.1037/0893-3200.8.2.123.

[28] Krishnakumar A, Buehler C. Interparental Conflict and Parenting Behaviors: A Meta-Analytic Review. Fam Relat 2000;49:2544. https://doi.org/10.1111/j.1741-3729.2000.00025.x.

[29] Erel O, Burman B. Interrelatedness of marital relations and parent-child relations: A meta-analytic review. Psychol Bull 1995;118:108-32. https://doi.org/10.1037/0033-2909.118.1.108.

[30] Bradford K, Vaughn LB, Barber BK. When there is conflict: Interparental conflict, parent-child conflict, and youth problem behaviors. J Fam Issues 2008;29:780-805. https://doi.org/10.1177/0192513X07308043.

[31] Stone G, Buehler C, Barber BK. Interparental conflict, parental psychological control, and youth problem behavior. Intrusive Parent. How Psychol. Control Affect. Child. Adolesc., American Psychological Association; 2004, p. 53-95. https://doi.org/10.1037/10422-003.

[32] El Kazdouh H, El-Ammari A, Bouftini S, El Fakir S, El Achhab Y. Potential risk and protective factors of substance use among school adolescents in Morocco: A cross-sectional study. J Subst Use 2019;24:176-83. https://doi.org/10.1080/14659891.2018.1535003.

[33] Alwan H, Viswanathan B, Rousson V, Paccaud F, Bovet P. Association between substance use and psychosocial characteristics among adolescents of the Seychelles. BMC Pediatr 2011;11:85. https://doi.org/10.1186/1471-2431-11-85.

[34] Peltzer K. Prevalence and correlates of substance use among school children in six African countries. Int J Psychol 2009;44:378-86. https://doi.org/10.1080/00207590802511742.

[35] Clark TT, Nguyen AB. Family factors and mediators of substance use among African American adolescents. J Drug Issues 2012;42:358-72. https://doi.org/10.1177/0022042612461770.

[36] Kliewer W, Murrelle L. Risk and Protective Factors for Adolescent Substance Use: Findings from a Study in Selected Central American Countries. J Adolesc Heal 2007;40:448-55. https://doi.org/10.1016/j.jadohealth.2006.11.148.

[37] Kementerian Kesehatan. Warta Kesmas: Keluarga Sehat Wujudkan Indonesia Sehat. Ed 03 2017:5-48.

[38] Program Indonesia Sehat dengan Pendekatan Keluarga - PISPK n.d. http://pispk.kemkes.go.id/id/programpispk/pelaksanaan-pendekatan-keluarga-sehat/ (accessed August 19, 2021).

[39] Samek DR, Keyes MA, Hicks BM, Bailey J, McGue M, Iacono WG. General and specific predictors of nicotine and alcohol dependence in early adulthood: genetic and environmental influences. J Stud Alcohol Drugs 2014;75:623-34. https://doi.org/10.15288/jsad.2014.75.623.

[40] Le TN, Kato T. The role of peer, parent, and culture in risky sexual behavior for Cambodian and Lao/Mien adolescents. J Adolesc Heal 2006;38:288-96. https://doi.org/10.1016/J.JADOHEALTH.2004.12.005. 